\title{
The Role of Interval Nodes in Sentinel Lymph Node Mapping and Dissection for Melanoma Patients
}

\author{
Maurice Matter ${ }^{1}$, Marie Nicod Lalonde ${ }^{2}$, Mohamed Allaoua ${ }^{2}$, Ariane Boubaker ${ }^{2}$, Danielle Liénard ${ }^{3}$, Oliver Gugerli ${ }^{4,5}$, \\ Jean-Philippe Cerottini ${ }^{5}$, Hanifa Bouzourene ${ }^{4}$, Angelika Bischof Delaloye ${ }^{2}$, and Ferdinand Lejeune ${ }^{1,3}$ \\ ${ }^{1}$ Department of Visceral Surgery, Centre Hospitalier Universitaire Vaudois, Lausanne, Switzerland; ${ }^{2}$ Department of Nuclear Medicine, \\ Centre Hospitalier Universitaire Vaudois, Lausanne, Switzerland; ${ }^{3}$ Department of Oncology, Centre Hospitalier Universitaire Vaudois, \\ Lausanne, Switzerland; ${ }^{4}$ Department of Pathology, Centre Hospitalier Universitaire Vaudois, Lausanne, Switzerland; and ${ }^{5}$ Department \\ of Dermatology, Centre Hospitalier Universitaire Vaudois, Lausanne, Switzerland
}

In sentinel node (SN) biopsy, an interval $\mathrm{SN}$ is defined as a lymph node or group of lymph nodes located between the primary melanoma and an anatomically well-defined lymph node group directly draining the skin. As shown in previous reports, these interval SNs seem to be at the same metastatic risk as are SNs in the usual, classic areas. This study aimed to review the incidence, lymphatic anatomy, and metastatic risk of interval SNs. Methods: SN biopsy was performed at a tertiary center by a single surgical team on a cohort of 402 consecutive patients with primary melanoma. The triple technique of localization was used-that is, lymphoscintigraphy, blue dye, and $\gamma$-probe. Otolaryngologic melanoma and mucosal melanoma were excluded from this analysis. SNs were examined by serial sectioning and immunohistochemistry. All patients with metastatic SNs were recommended to undergo a radical selective lymph node dissection. Results: The primary locations of the melanomas included the trunk (188), an upper limb (67), or a lower limb (147). Overall, $97(24.1 \%)$ of the 402 SNs were metastatic. Interval SNs were observed in 18 patients, in all but 2 of whom classic SNs were also found. The location of the primary was truncal in $11(61 \%)$ of the 18 , upper limb in 5 , and lower limb in 2 . One patient with a dorsal melanoma had drainage exclusively in a cervicoscapular area that was shown on removal to contain not lymph node tissue but only a blue lymph channel without tumor cells. Apart from the interval SN, 13 patients had 1 classic SN area and 3 patients 2 classic SN areas. Of the 18 patients, 2 had at least 1 metastatic interval $\mathrm{SN}$ and 2 had a classic SN that was metastatic; overall, $4(22.2 \%)$ of 18 patients were node-positive. Conclusion: We found that 2 of 18 interval SNs were metastatic: This study showed that preoperative lymphoscintigraphy must review all known lymphatic areas in order to exclude an interval SN.

Key Words: melanoma; sentinel lymph node dissection; interval node

J Nucl Med 2007; 48:1607-1613

DOI: 10.2967/jnumed.107.041707

Received Mar. 13, 2007; revision accepted Jul. 11, 2007.

For correspondence or reprints contact: Maurice Matter, MD, Service de Chirurgie Viscérale, Rue du Bugnon 46, 1011 Lausanne-CHUV, Switzerland. E-mail: maurice.matter@chuv.ch

COPYRIGHT ( 2007 by the Society of Nuclear Medicine, Inc.
$\mathbf{T}$ he treatment of malignant melanoma patients is based mainly on surgical techniques, which can provide for disease resection and staging. In such surgeries, the sentinel node (SN) has been defined as the first lymph node directly draining the cutaneous site of the primary melanoma (1). Indeed, in more than $95 \%$ of occult metastases, metastasis can be detected in the SN. The method for detecting the $\mathrm{SN}$, or "SN biopsy," has been described extensively since its original description in 1992 (1). The third interim analysis of the results of the Multicenter Selective Lymphadenectomy Trial I showed that in patients with intermediate-thickness melanoma, survival was improved over that with observation alone when $\mathrm{SN}$ biopsy revealed micrometastases in the $\mathrm{SN}$ and was followed by radical selective lymph node dissection (2). Most reports refer to SNs situated in the classic lymph node basins: mainly the cervical, axillary, and groin. In contrast, an interval SN is defined as an unexpected, unusual lymph node or group of lymph nodes located between the primary melanoma and the classic basins. The problem with interval SNs has already been described (3), and its relevance needs to be further evaluated. Theoretically and as shown in many reports, the interval SNs are at the same metastatic risk as are SNs in the usual, classic areas (3).

Switzerland has one the highest incidences of melanoma in Europe, and that incidence has been rising (from 5.7 per 100,000 inhabitants in $1978-1982$ to 16.8 per 100,000 in 1998-2002) (4). The aim of this study was to evaluate the incidence, anatomy, and metastatic risk of interval SNs in a large cohort of patients at a tertiary referral center for melanoma.

\section{MATERIALS AND METHODS}

\section{Patients}

Since 1997, all patients who had clinically and radiologically N0 skin melanoma with a Breslow thickness of more than $1 \mathrm{~mm}$ were prospectively included in a systematic SN biopsy program. Also included were patients whose melanoma had a Breslow thickness of $1 \mathrm{~mm}$ or less but was also Clark IV, ulcerated, or 
regressed. Patients who had a local recurrence of previous melanoma that had been operated on before 1997 entered the program but were excluded from the present analysis. Patients who had melanoma of the head and neck were also excluded from the present analysis, because of less predictable SN identification (5). All patients underwent abdominal and thoracic CT to detect any suggestive lesions.

\section{SN Biopsy}

In all but 1 patient, $\mathrm{SNs}$ were identified using the triplelocalization technique with lymphoscintigraphy, blue dye, and $\gamma$-probe. One recently pregnant patient underwent blue-dye localization only and aborted after a positive SN was found. Lymphoscintigraphy was performed on the day before surgery. Depending on the size of the scar, 2-4 intradermal injections of $10 \mathrm{MBq}$ of 99mTc-nanocolloid in $0.1 \mathrm{~mL}$ were made around the excision/ biopsy scar ( ${ }^{99 \mathrm{~m} T c-l a b e l e d ~ h u m a n ~ s e r u m ~ a l b u m i n ~ n a n o c o l l o i d, ~}$ particles $<80 \mathrm{~nm}$, Nanocoll; Amersham Health). Dynamic imaging was then performed for $15 \mathrm{~min}(128 \times 128$ matrix, 60 frames, $15 \mathrm{~s} /$ frame) to identify the draining lymphatic vessels and to follow them until they reached the draining SN. The dynamic imaging was then followed by acquisition of static planar images $(256 \times 256$ matrix, 5 min/image $)$ over any lymph node field that could possibly drain the primary site. The imaging was completed by static transmission imaging using a ${ }^{57} \mathrm{Co}$ sheet $(256 \times 256$ matrix, $2 \mathrm{~min} / \mathrm{image}$ ). Images were acquired with a single- or multihead $\gamma$-camera with low-energy high-resolution collimators. The surface location of the SNs was marked after localization with a hand-held $\gamma$-probe (Scintiprobe; Pol.Hi.Tech, then neo2000; Neoprobe Corp.) or an external ${ }^{57}$ Co pen. On the day of surgery, a total of $2 \mathrm{~mL}$ (i.e., $4 \times 0.5 \mathrm{~mL}$ ) of blue dye (bleu patenté violet; Laboratoire Guerbet) were injected intradermally at 4 points around the scar or the primary. Surgery was directed by the same $\gamma$-probe, with systematic exploration of all possible basins. The SNs were dissected first, and then the scar was removed along with the usual safety margins.

\section{Histopathology}

The SNs, either fresh or in formaldehyde solution, were sent directly to the Department of Pathology. The lymph nodes were bivalved, embedded in paraffin, and sectioned for hematoxylineosin and immunohistochemistry staining (Melan A and protein S100), but no polymerase chain reaction analysis was performed. When an interval SN was discovered, the entire local lymph node group was directly removed, with the exception of the popliteal basin. Radical selective lymph node dissection was recommended for all patients with metastatic SNs. Patients were followed up with a clinical examination every 3-6 mo and with CT regularly.

\section{RESULTS}

Between October 1997 and January 2007, 451 melanoma patients were admitted at our center and managed by the same team of 3 surgeons. Forty-nine patients did not fit the inclusion requirements and were excluded from the study. The analyzed cohort consisted of 402 patients with primary cutaneous melanoma of the limbs or trunk. SNs were detected in all but 3 patients $(0.7 \%) ; 2$ patients had 2 basins each and underwent a complete radical dissection of the failed SN basin. In the third patient, only an "interval SN-hot spot" was detected. Among the 402 patients, 188 showed the primary to be localized to the trunk, 67 to an upper limb, and 147 to a lower limb. Overall, 97 (24.1\%) of 402 patients had at least 1 metastatic SN. Lymphoscintigraphy detected 1 basin in 317 patients, 2 basins in 75 patients, and 3 basins in 9 patients. Overall, 494 basin dissections were performed.

Eighteen patients $(4.5 \%)$ had 1 interval SN, and all but 2 had a classic SN (Fig. 1; Table 1). In 11 of these 18 patients, the primary melanoma was dorsal, paravertebral, scapular, or lumbar, representing $5.9 \%$ of truncal melanomas. Five patients had upper-limb (7.5\%) and 2 had lowerlimb (1.4\%) melanomas (Table 2).

Results on SNs, interval SN distributions, and survival are presented in Figures 2-7. One patient with a Breslow 0.95 Clark III dorsal superficial spreading melanoma had drainage exclusively in a cervicoscapular hot-spot area (Fig. 3) that was shown on removal to contain only a blue lymph channel; no lymph node or tumor was identified. No other cervical or axillary SN was detected, and no further treatment was proposed. Another patient with a nodular Breslow 4.1 Clark IV melanoma of the dorsal forearm had drainage exclusively parallel to the cephalic vein, with 1 humeral SN and 3 subclavian SNs but no axillary SN (Fig. 7). Regarding the other 16 patients, 13 had 1 classic SN and 3 had 2 classic SNs (Table 1). Two patients (11.1\%) of the 18 had a metastatic interval SN (patients 1 and 17 , Table 1). In 1 of these, the classic axillary SN was not metastatic. Axillary dissection was not proposed for that patient, who died 13 mo later with widespread disease. Two patients had a classic SN that was metastatic (patients 2 and 4). Patient 2 had an axillary selective lymph node dissection

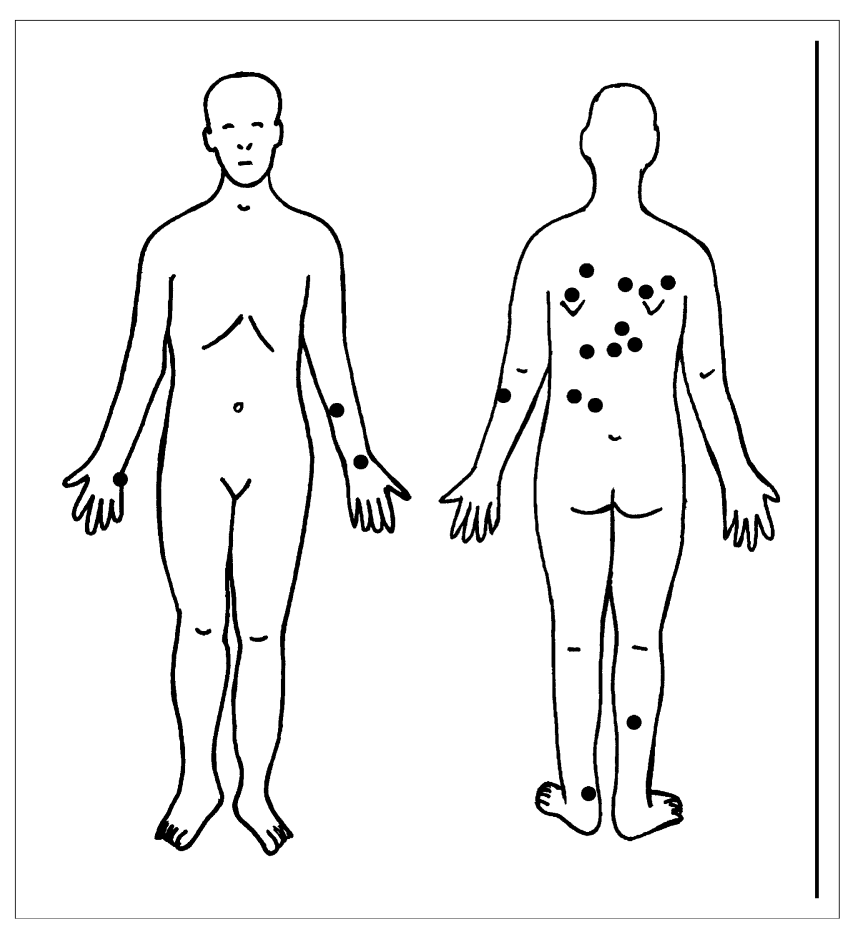

FIGURE 1. Location of primary tumors with interval SNs. 
TABLE 1

Patients with Interval SNs

\begin{tabular}{|c|c|c|c|c|c|c|c|c|c|c|}
\hline $\begin{array}{l}\text { Patient } \\
\text { no. }\end{array}$ & Sex & $\begin{array}{l}\text { Age } \\
\text { (y) }\end{array}$ & Melanoma & Breslow & Clark & Location & Interval SN & Other SN 1 & Other SN 2 & Survival* \\
\hline 1 & M & 62 & ALM & 3.8 & IV & $\mathrm{R}$ third finger & 1/1 cubital & 0/1 axillary & & 13 DOD \\
\hline 2 & M & 52 & $\mathrm{U}, \mathrm{Na}$ & 5.5 & V & $\begin{array}{l}\mathrm{R} \text { hypothenar } \\
\text { eminence }\end{array}$ & 0/1 humeral & 1/1 axillary & & 43 ITM, DOD \\
\hline 3 & $\mathrm{~F}$ & 56 & SSM & $0.5^{\dagger}$ & III & L paravertebral & 0/2 scapular & $0 / 3$ axillary & & 69 NED \\
\hline 4 & M & 35 & SSM & 3.0 & IV & $\mathrm{R}$ paravertebral & 0/1 dorsal & 1/1 axillary & & $21 \mathrm{AXM}, \mathrm{DOD}$ \\
\hline 5 & $\mathrm{~F}$ & 63 & $\mathrm{~N}^{\ddagger}$ & 3.0 & IV & L scapular & 0/1 scapular & 0/1 cervical & & 66 NED \\
\hline 6 & $\mathrm{M}$ & 43 & $U^{\ddagger}$ & 3.9 & IV & $\mathrm{R}$ calf & 0/1 popliteal & $0 / 1$ femoral & $0 / 2$ inguinal & 57 NED \\
\hline 7 & $\mathrm{M}$ & 57 & $\mathrm{SSM}, \mathrm{Na}$ & 0.8 & IV & R scapular & 0/2 scapular & $0 / 5$ axillary & & 57 NED \\
\hline 8 & $\mathrm{~F}$ & 26 & $S$ & 1.3 & III & L wrist & $0 / 1$ humeral & $0 / 1$ axillary & & 52 NED \\
\hline 9 & $M$ & 67 & $\mathrm{~N}^{\ddagger}$ & 1.1 & III & $\mathrm{R}$ dorsal & 0/1 scapular & $0 / 3$ axillary & & 48 NED \\
\hline 10 & $\mathrm{~F}$ & 34 & $\mathrm{~N}$ & 0.9 & IV & $L$ forearm & 0/1 cubital & 0/1 axillary & & 48 NED \\
\hline 11 & $\mathrm{~F}$ & 36 & SSM & $0.5^{\dagger}$ & III & Middle dorsal & 0/2 scapular $R$ & $0 / 1$ axillary $R$ & $0 / 2$ axillary $L$ & 43 NED \\
\hline 12 & $\mathrm{M}$ & 44 & $\mathrm{~N}$ & 1.5 & IV & L dorsal & 0/1 dorsal $L$ & $0 / 3$ axillary & & 36 NED \\
\hline 13 & $M$ & 73 & $\mathrm{SSM}^{\ddagger}$ & 1.2 & III & $\mathrm{R}$ dorsal & 0/1 scapular $\S$ & $0 / 1$ axillary & & 34 NED \\
\hline 14 & $\mathrm{M}$ & 67 & SSM & 1.1 & IV & L lumbar & 0/2 lumbar & $0 / 1$ inguinal & $0 / 3$ axillary & 15 NED \\
\hline 15 & $M$ & 0 & SSM & 0.95 & III & L shoulder & 0/0 scapularll & - & & 9 NED \\
\hline 16 & $\mathrm{~F}$ & 45 & SSM, Na & 1.7 & IV & L lumbar & $0 / 1$ intercostal & 0/4 inguinal & & 8 NED \\
\hline 17 & $\mathrm{~F}$ & 73 & SSM & 2.4 & IV & L Achilles' tendon & 2/4 popliteal & $2 / 4$ inguinal & & 1 NED \\
\hline 18 & $\mathrm{~F}$ & 75 & $\mathrm{~N}$ & 4.1 & IV & $L$ forearm & $0 / 1$ cephalic vein & $\begin{array}{l}\text { 0/3 distal cephalic } \\
\text { vein (ISN) }\end{array}$ & & 1 NED \\
\hline
\end{tabular}

${ }^{\star}$ Follow-up in months: DOD = died of disease; ITM = in-transit metastases; NED = no evidence of disease; AXM = axillary metastases. ${ }^{\dagger}$ With regression.

‡With ulceration.

§Only nonblue SN.

"Lymphatic channel was identified only in hot dissected tissues, without any other lymph drainage area.

"No classic SN.

ALM = acral-lentiginous; $U$ = unclassified; $N=$ nodular; SSM = superficial spreading melanoma; $N a=$ on a nevi; $S=$ spitzoid.

Data for Interval SN, Other SN 1, and Other SN 2 are number of metastatic SNs/number of detected SNs and location of these nodes.

with no further metastatic nodes (0/9) but presented with transit metastases after 17 mo and died at 43 mo with multiple distant metastases. Patient 4 had metastatic nonSNs in the selective lymph node dissection (3/30) and died 21 mo later with axillary recurrence and multiple pulmonary and liver metastases. After a median follow-up of 48 mo (range, 1-69 mo), the other 15 patients are well and show no evidence of disease. Overall, 4 (22.2\%) of 18 patients were node-positive.

\section{DISCUSSION}

\section{Concept and Definition}

Even with an incidence of only $4.5 \%$ in the present large series, interval SNs are a relevant problem. The terminol- ogy and definition of interval SNs must be discussed. A prerequisite is to accept that the usual classic basins comprise the cervical, axillary, inguinal, and iliac lymph node chains. Possible anatomically known but unusual basins include the subclavicular, internal mammary (retrosternal), and popliteal lymph nodes, for which radical lymph node dissection has been well described. In addition, one can find isolated or small groups of lymph nodes in rare but anatomically already-defined areas such as the epitrochlear area (6), humeral area, triangular intermuscular space (7), interpectoral area (4), intercostal areas (axillary line $(8)$ and paravertebral $(9,10))$, paraaortic and retroperitoneal areas $(4,11)$, lumbar area, calf, and thigh (12). The term interval node should include the last 2 groups and

TABLE 2

Location of Primary and Interval SN

\begin{tabular}{ccc}
\hline No. of patients & Primary & Interval SN \\
\hline 11 & Truncal (5.9\%) (3 scapular, 6 dorsal, 2 lumbar) & 6 triangular intermuscular space \\
& & 3 cervicoscapular (subcutaneous) \\
& & 1 intercostal (10th space) \\
& & 1 lumbar (Grynfeltt's superior triangle) \\
5 & Upper limb (7.5\%) & 2 cubital, 2 humeral \\
2 & Lower limb (1.4\%) & 2 cephalic vein \\
\hline
\end{tabular}


FIGURE 2. Triangular intermuscular space: patient 11, with Breslow 0.46 (with regression) Clark III upper dorsal superficial spreading melanoma (interval SNs [ISNs] 1 and 2 in right triangular intermuscular space, $1 \mathrm{SN}$ in right axilla, and SNs 1 and 2 in left axilla [all nonmetastatic]).
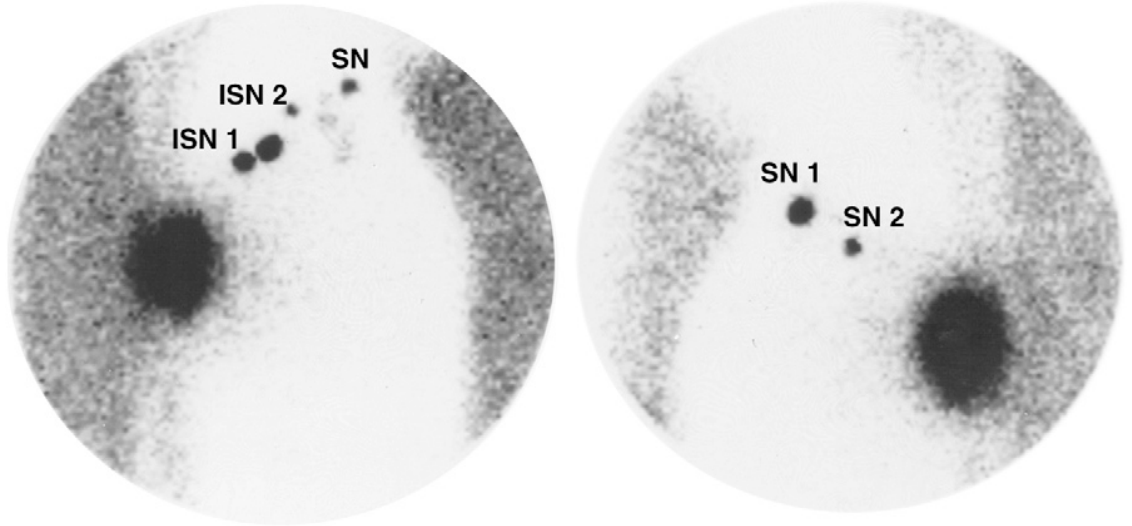

seems more appropriate than the terms unusual node, in-transit node, ectopic node, node outside lymph node basins, or intercalated nodes.

\section{Incidence and Anatomy}

Preoperative lymphoscintigraphy enhances lymphatic anatomy and definitively shows all potential SN areas (3). Lymphoscintigraphy can demonstrate multiple lymph drainage basins for melanomas located around the watershed areas (midline and umbilicus level) and, moreover, can review all other lymphatic drainage to disclose any interval SNs. The incidence of interval SNs varies widely, from $3.1 \%$ to $9.8 \%$ (Table 2) (11-19). We observed interval nodes in $4.5 \%$ of cases. The wide variation in interval SN incidence can be explained by differences in definition, in centers, in types of imaging tracers $(20,21)$, in tracer injection $(22,23)$, and in percentage of interval SN dissection. We deliberately chose to exclude otolaryngologic melanomas (separate analysis), for which large series $(4,13)$ have found a $4.2 \%-6.8 \%$ incidence of interval SNs. An important point was further highlighted by Thelmo et al. (19). High-quality analysis requires acquisition of dynamic and static lymphoscintigraphy images in order to evaluate 2

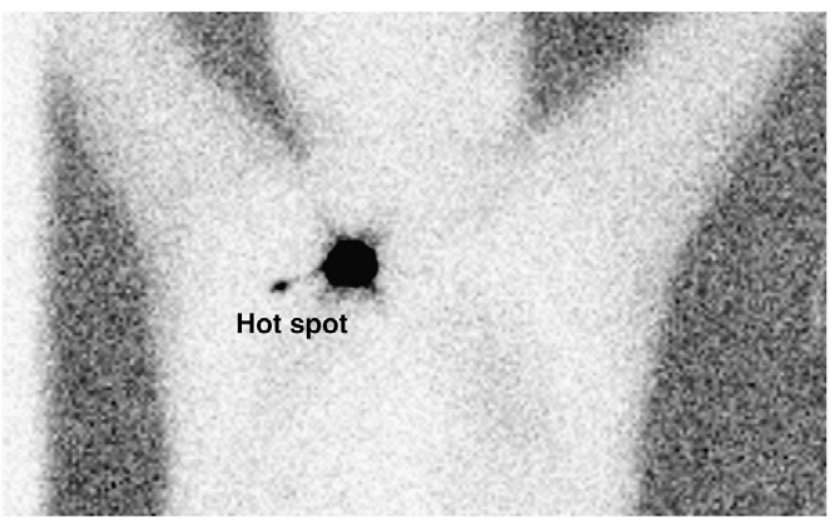

FIGURE 3. Cervicoscapular: patient 15, with Breslow 0.95 (with regression) Clark III superficial spreading melanoma of left shoulder (removal and analysis of hot spot showed no interval $\mathrm{SN}$ and no tumor cells). types of lymphatic channels: serial and parallel $(14,19,24)$. In a serial type of lymphatic channel, an interval $\mathrm{SN}$ could be a first-tier SN whereas the distal SN in the usual basin could be a second-tier SN. A parallel type of lymphatic channel would challenge the concept that the $\mathrm{SN}$ is the hottest, nearest node (25). Analysis of the counts per minute and the blue dye cannot differentiate a parallel channel from a unique channel, because of the resolution of the preoperative lymphoscintigraphy (19). Finally, lymphoscintigraphy may show hot spots that do not correspond to

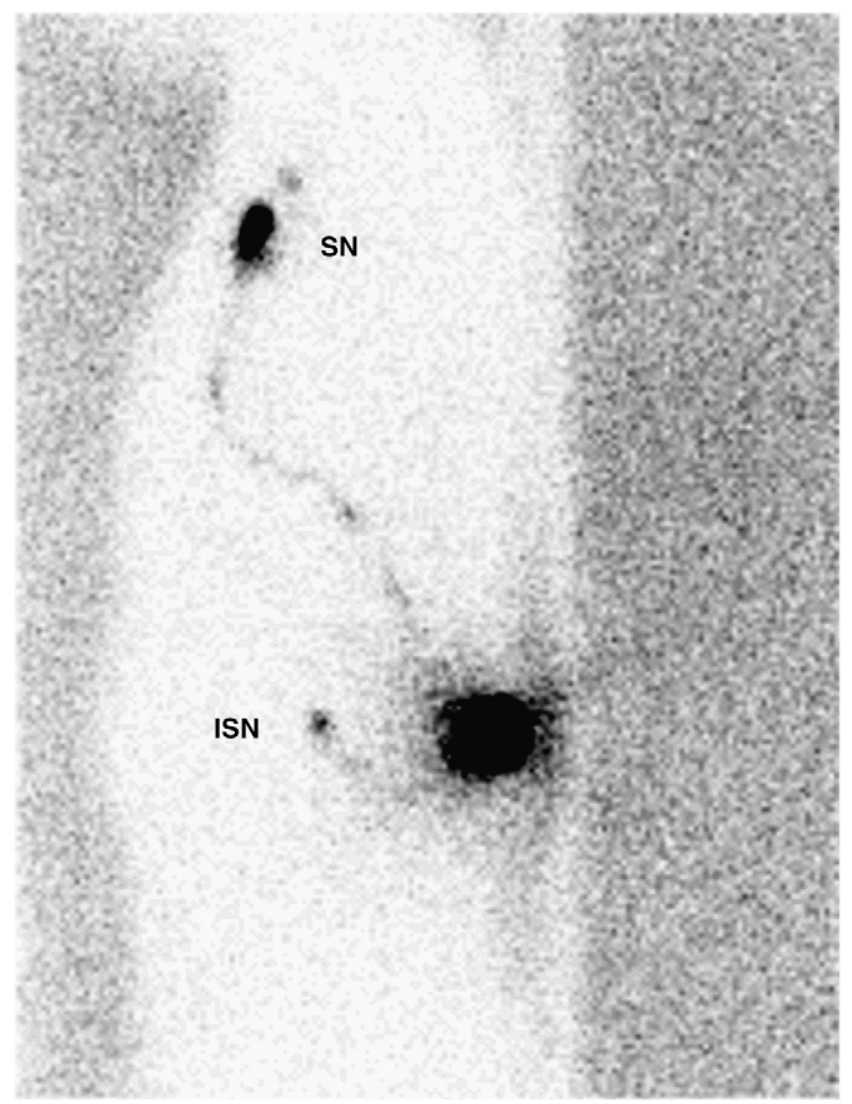

FIGURE 4. Intercostal: patient 16, with Breslow 1.65 Clark IV left lumbar superficial spreading melanoma (interval SN [ISN] in 10th intercostal space and left axillary SN were nonmetastatic). 


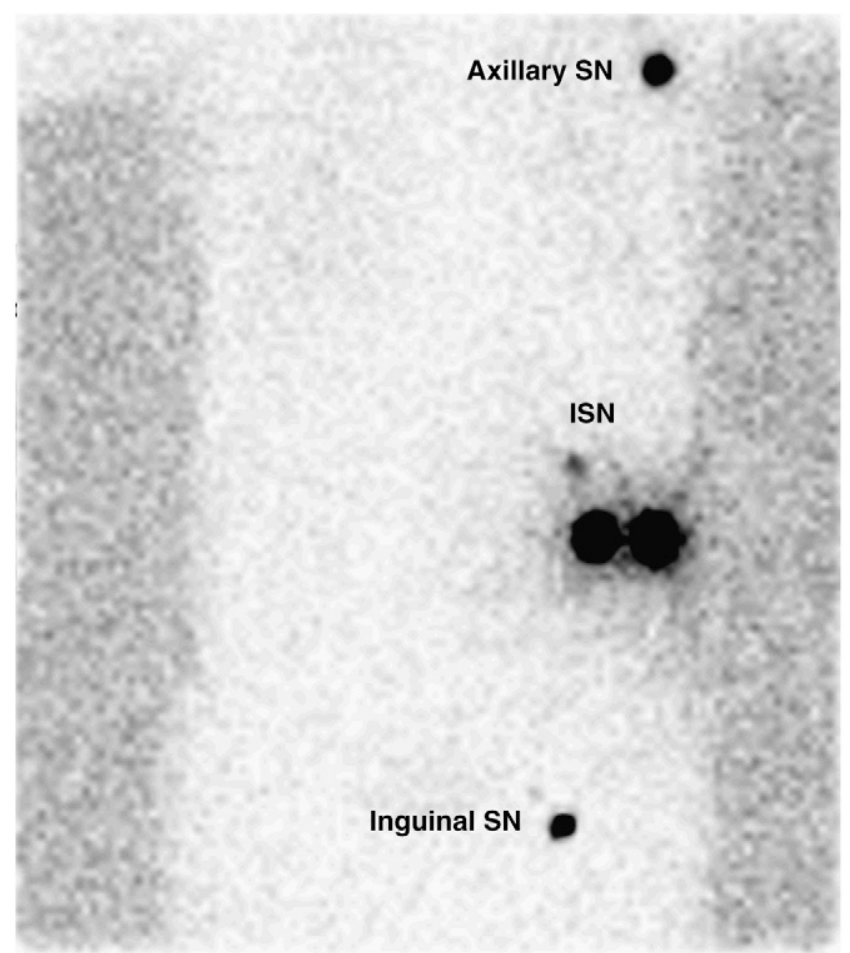

FIGURE 5. Lumbar superior Grynfeltt's triangle: patient 14, with Breslow 1.1 Clark IV left lumbar superficial spreading melanoma (interval SN [ISN], 1 left inguinal SN, and 3 left axillary SNs were nonmetastatic).

lymph nodes: Vidal-Sicart et al. found in 2 of 61 interval SNs hot spots that were actually 1 lymphatic lake and 1 lymphangioma (17). Similarly, Roozendaal et al. found in 3 of 25 interval SNs a hot spot that was a case of lymphangioma and hot spots in 2 other patients who had no lymph node tissue on histologic examination of the hot-spot area (15).

The incidence of interval SNs varies regarding melanoma location. We found that patients with melanomas on the trunk (5.9\%) or upper limb (7.5\%) had the highest proportion of interval SNs, whereas the incidence dropped in patients with lower-limb melanomas (1.4\%). This finding had already been reported in the largest published series (Table 2). These reports recommended that investigators obtain systematic lymphoscintigraphic views of all expected and possible SN locations, as we did in the present study. Lumbar melanomas have some peculiarities, because their lymphatic drainage is highly unpredictable and they have the highest incidence of interval SNs-twice that found in other locations $(4,14)$. We observed a rare anterior intercostal lymph node on the axillary line (patient 16, Fig. 4), a finding never observed by Weinberg (8). Another interval SN (patient 14, Fig. 5) was found in the superior lumbar triangle of Grynfeltt. This triangle is known for protrusions and lumbar hernias (26). Compared with the inferior lumbar triangle of Petit, the superior triangle can exhibit a vasculonervous bundle that can be accompanied by lymphatic vessels or nodes in the same way as is the

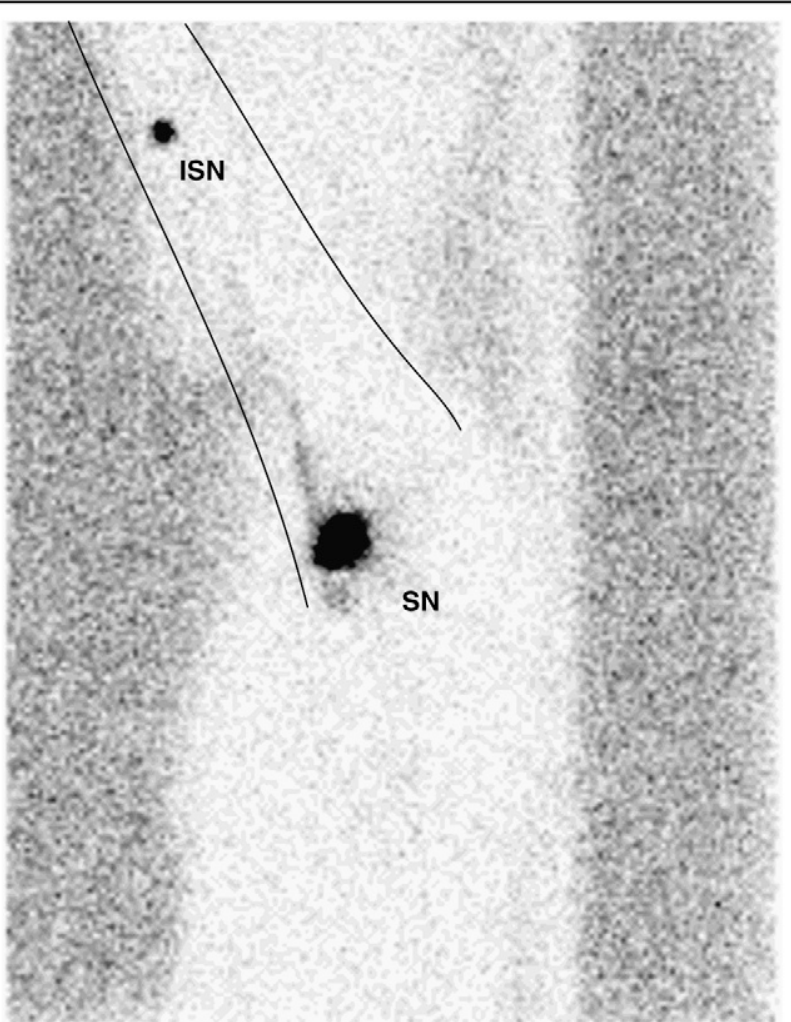

FIGURE 6. Humeral: patient 8, with spitzoid Breslow 1.3 Clark III melanoma of left wrist (humeral interval SN (ISN) and 1 axillary $\mathrm{SN}$ were nonmetastatic). Arms are raised.

triangular intermuscular space in the shoulder. This bundle may represent the entrance of lymph flow directed to retroperitoneal and paraaortic nodes and could provide a less invasive way to surgically access these nodes. Patient 18 had exclusive lymphatic drainage that paralleled the cephalic vein, with 1 humeral SN and 3 SNs before the cephalic vein plunged under the clavicle (Fig. 7). Such drainage has already been described by Thompson et al. (3) and Haagensen (27), but the absence of axillary drainage is notable.

\section{Surgical Treatment}

The main reasons to search for and remove detected interval SNs are, first, because the risk of metastasis $(0 \%-$ $22 \%$ ) is similar to that of other SNs and, second, because the interval SN may be the only metastatic site, as was the case in $4(7.4 \%)$ of 54 patients in one study (16), 5 (8.5\%) of 59 in another (17), $3(10 \%)$ of 30 in a third (19), 3 $(14.3 \%)$ of 21 in a fourth (14), and $11(17.7 \%)$ of 62 in a fifth (13). Suspected interval SNs should be resected, and Uren et al. speculated that some in-transit metastases could actually be undissected/undetected interval SNs (14). For example, Statius Muller et al. observed 44 recurrences in 248 patients after a median follow-up of 38 mo; among them, 2 were recurrences in interval SNs (28). The interval SN may also be the only lymph node drainage, as in patient 18. 

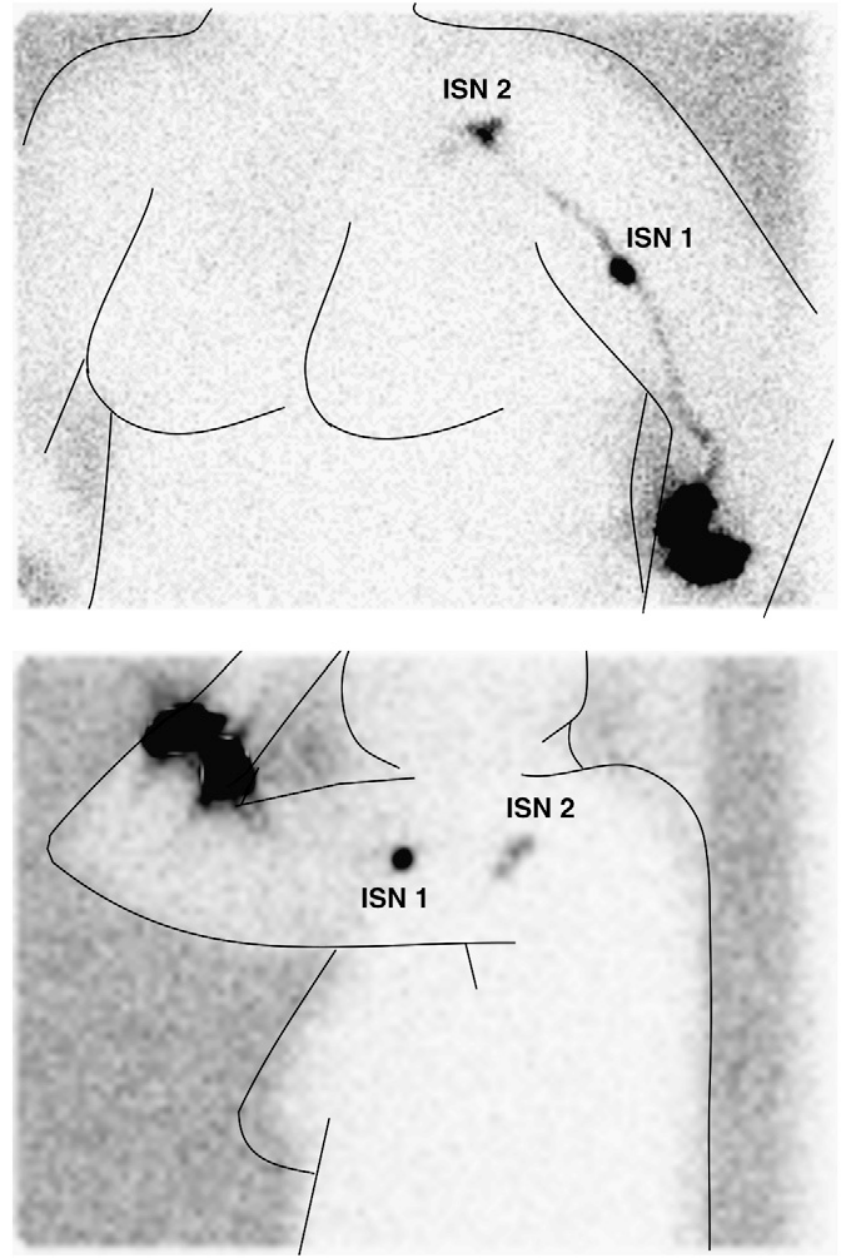

FIGURE 7. Cephalic vein: 2 views of patient 18, with nodular Breslow 4.1 Clark IV left forearm melanoma (interval SNs [ISNs] on arm and in infraclavicular fossa were nonmetastatic). Note absence of axillary drainage.

We explored all hot spots regarded as interval SNs. Not all previously reported studies used this systematic surgical search, with some authors considering the procedure as excessive or dangerous (paraaortic, for example). Dissection of the internal mammary lymph node (including the $\mathrm{SN}$ ) is a well-known technique in breast cancer surgery
$(29,30)$, and laparoscopic handheld $\gamma$-probes are available. Thus, it is possible that the incidence of interval SNs would have been lower if all interval SNs had been dissected, thereby allowing the exclusion of lymphatic lakes. In the paper published in 2000 by Uren et al., only 21 of 148 interval SNs were dissected (14). Our experience yielded hot spots in interval-SN locations in 18 patients. Patient 15 deserves special mention because the location of the interval$\mathrm{SN}$ hot spot was a lymph channel and there was no classic or other SN. Anatomic and physiologic studies on lymphatic circulation show that the lymphatic stream may bypass a local obstacle by using parallel, previously nonfunctional channels and an inverse flow direction. Increased lymphatic flow or an obstacle may distend ducts (31), possibly explaining the evanescent hot spots seen in some patients $(15,17)$. Because tumor deposits have never been reported for lymphatic lakes, they must be definitively different from interval SNs (14).

\section{Further Management of Metastatic Interval SNs}

Unusual locations must be recognized and distinguished from regional or distant metastatic disease (16). When a metastatic interval $\mathrm{SN}$ is detected, most investigators believe that definitive treatment should include a radical regional resection of surrounding soft tissues and lymph nodes. In our surgical experience, during the initial dissection of the interval SN we have directly removed all other surrounding lymph nodes to avoid difficulty with further dissections (of the triangular intermuscular space, for example), with the exception of popliteal interval SNs. The popliteal is the principal interval node in the lower limb, varying in incidence from $4.3 \%$ to $36 \%$ of cases $(3,32,33)$, and radical popliteal lymph node dissection is a validated surgical technique (34). Whether to perform a radical selective lymph node dissection of the distal basin or another basin when the classic $\mathrm{SN}$ is not metastatic is still a matter of debate. The strategy of Sumner et al. is to perform a radical selective lymph node dissection of the regional lymph node basin upstream from the interval SN (16), and Roozendaal et al. believe that a metastatic interval SN may indicate involvement of the subsequent lymph node basin (15). In contrast, having confidence in the

TABLE 3

Review of the Literature: Interval SNs in Melanoma Patients

\begin{tabular}{lrrrrrrr}
\hline Study & Patients & Interval SNs & Trunk (\%) & $\begin{array}{c}\text { Upper } \\
\text { limb (\%) }\end{array}$ & $\begin{array}{c}\text { Lower } \\
\text { limb (\%) }\end{array}$ & $\begin{array}{c}\text { Overall } \\
\text { metastatic (\%) }\end{array}$ & $\begin{array}{c}\text { Metastatic } \\
\text { interval SNs }\end{array}$ \\
\hline McMasters (13) & 2,000 & $62(3.1 \%)$ & 2.7 & 3.8 & 2.0 & 19.5 & $13 / 64(20.3 \%)$ \\
Uren (14) & 2,045 & $148(7.2 \%)$ & 11.8 & 4.7 & 0.9 & $3 / 21(14.3 \%)$ \\
Roozendaal (15) & 379 & $23(6.1 \%)$ & 8.3 & 12.1 & 2.0 & & $4 / 18(22.2 \%)$ \\
Summer (16) & 1,117 & $59(5.3 \%)$ & 6.9 & 3.9 & 2.3 & 16.9 & $7 / 54(13.0 \%)$ \\
Vidal-Sicart (17) & 599 & $59(9.8 \%)$ & 15.1 & 12.1 & 4.7 & 17.9 & $10 / 59(16.9 \%)$ \\
Chakera (11) & 241 & $22(9.1 \%)$ & & & & 22.0 & $0 / 8(0 \%)$ \\
Doting (18) & 200 & $17(8.5 \%)$ & & & & 24.2 & $2 / 17(11.8 \%)$ \\
Thelmo (19) & 557 & $30(5.4 \%)$ & & & & 24.1 & $5 / 30(16.7 \%)$ \\
Chakera (11) & 402 & $18(4.6 \%)$ & 5.9 & 7.5 & 1.4 & & $0 / 8(0 \%)$ \\
\hline
\end{tabular}


accuracy of SN biopsy to detect micrometastatic disease, McMasters et al. recommended that negative SN basins not undergo surgery (13). Regarding these recommendations, our opinion is that they increase the risk of undertreatment and that more work is needed on interval SNs before recommendations can be made.

\section{CONCLUSION}

With $2(11.1 \%)$ of 18 interval SNs found to be metastatic-a percentage that compares favorably with what has been reported in the literature (Table 3) - this study showed that preoperative lymphoscintigraphy must cover all known lymphatic areas so that the interval SNs can be identified and removed. Good knowledge of the anatomy of lymphatic drainage is mandatory to allow appropriate surgical therapy to be offered. Because the morphometric tumor burden in SNs is not universally and accurately predictive of the positivity or negativity of non-SNs (35), this criterion should be evaluated in interval SNs as well. To definitively establish whether positive interval SNs truly are active regional metastases, a large collection of reference data on interval SNs is needed and could be obtained with the creation of a prospective registry.

\section{ACKNOWLEDGMENTS}

This study was presented in part at the joint conference of Perspectives in Melanoma X and the third International Melanoma Research Congress, at the fifth biennial meeting of the International Sentinel Node Society, and at the 13th congress of the European Society of Surgical Oncology. We thank David Guggisberg for reviewing the manuscript.

\section{REFERENCES}

1. Morton DL, Wen D-R, Wong JH, et al. Technical details of intraoperative lymphatic mapping for early stage melanoma. Arch Surg. 1992;127:392-399.

2. Morton DL, Thompson JF, Cochran AJ, et al. Sentinel-node biopsy or nodal observation in melanoma. N Engl J Med. 2006;355:1307-1317.

3. Thompson JF, Uren RF, Shaw HM, et al. Location of sentinel lymph nodes in patients with cutaneous melanoma: new insights into lymphatic anatomy. $\mathrm{J} \mathrm{Am}$ Coll Surg. 1999;189:195-206.

4. Levi F, Te V-C, Randimbison L, La Vecchia C. Trends in incidence of various morphologies of malignant melanoma in Vaud and Neuchâtel, Switzerland. Melanoma Res. 2005;15:73-75.

5. Fincher TR, O'Brien JC, McCarty TM, et al. Patterns of drainage and recurrence following sentinel lymph node biopsy for cutaneous melanoma of the head and neck. Arch Otolaryngol Head Neck Surg. 2004;130:844-848.

6. Hunt JA, Thompson JF, Uren RF, Howman-Giles R, Harman CR. Epitrochlear lymph nodes as a site of melanoma metastasis. Ann Surg Oncol. 1998;5:248-252.

7. Uren RF, Howman-Giles R, Thompson JF, et al. Lymphatic drainage to triangular intermuscular space lymph nodes in melanoma on the back. J Nucl Med. 1996;37:964-966.

8. Weinberg JA. The intrathoracic lymphatics. In: Haagensen CD, Feind CR, Herter FP, Slanetz CA, Weinberg JA, eds. The Lymphatics in Cancer. Philadelphia, PA: W.B. Saunders; 1972:231-299.

9. Uren RF, Howman-Giles R, Thompson JF. Direct lymphatic drainage from a melanoma on the back to paravertebral lymph nodes in the thorax. Clin Nucl Med. 1999;24:388-389.
10. Iyer RB, Libshitz HI. Radiographic demonstration of intercostal lymphatics and lymph nodes. Lymphology. 1995;28:89-94.

11. Chakera AH, Drzewiecki KT, Eigtved A, Juhl BR. Sentinel node biopsy for melanoma: a study of 241 patients. Melanoma Res. 2004;14:521-526.

12. Estourgie SH, Nieweg OE, Valdès Olmos RA, Hoefnagel CA, Kroon BBR. Review and evaluation of sentinel node procedures in 250 melanoma patients with a median follow-up of 6 years. Ann Surg Oncol. 2003;10:681-688.

13. McMasters KM, Chao C, Wong SL, et al. Interval sentinel lymph nodes in melanoma. Arch Surg. 2002;137:543-549.

14. Uren RF, Howman-Giles R, Thompson JF, et al. Interval nodes: the forgotten sentinel nodes in patients with melanoma. Arch Surg. 2000;135:1168-1172.

15. Roozendaal GK, de Vries JDH, van Poll D, et al. Sentinel nodes outside lymph node basins in patients with melanoma. Br J Surg. 2001;88:305-308.

16. Sumner WE III, Ross MI, Mansfield PF, et al. Implications of lymphatic drainage to unusual sentinel lymph node sites in patients with primary cutaneous melanoma. Cancer. 2002;95:354-360.

17. Vidal-Sicart S, Pons F, Fuertes S, et al. Is the identification of in-transit sentinel lymph nodes in malignant melanoma patients really necessary? Eur J Nucl Med Mol Imaging. 2004;31:945-949.

18. Doting MH, Hoekstra HJ, Plukker JTM, et al. Is sentinel node biopsy beneficial in melanoma patients? A report on 200 patients with cutaneous melanoma. Eur J Surg Oncol. 2002;28:673-678.

19. Thelmo MC, Morita ET, Treseler PA, et al. Micrometastasis to in-transit lymph nodes from extremity and truncal malignant melanoma. Ann Surg Oncol. 2001;8: 444-448.

20. Boxen I, McCready D, Ballinger J. Sentinel node detection and definition may depend on the imaging agent and timing. Clin Nucl Med. 1999;24:390-394.

21. Kapteijn BA, Nieweg OE, Valdés Olmos RA, et al. Reproducibility of lymphoscintigraphy for lymphatic mapping in cutaneous melanoma. J Nucl Med. 1996;37:972-975.

22. Rossi CR, De Salvo GL, Trifirò G, et al. The impact of lymphoscintigraphy technique on the outcome of sentinel node biopsy in 1,313 patients with cutaneous melanoma: an Italian multicentric study (SOLISM-IMI). J Nucl Med. 2006;47:234-241.

23. Rettenbacher L, Koller J, Kässmann H, Holzmannhofer J, Rettenbacher T, Galvan G. Reproducibility of lymphoscintigraphy in cutaneous melanoma: can we accurately detect the sentinel lymph node by expanding the tracer injection distance from the tumor site? J Nucl Med. 2001;42:424-429.

24. Uren RF, Howman-Giles RB, Thompson JF. Demonstration of second-tier lymph nodes during preoperative lymphoscintigraphy for melanoma: incidence varies with primary tumor site. Ann Surg Oncol. 1998;5:517-521.

25. Nieweg OE, Estourgie SH. What is a sentinel node and what is a false-negative sentinel node? Ann Surg Oncol. 2004;11(suppl):169-173.

26. Geis WP, Saletta JD. Lumbar hernia. In: Nyhus LM, Condon RE, eds. Hernia. Philadelphia, PA: JB Lippincott; 1989:401-415.

27. Haagensen CD. The upper extremity. In: Haagensen CD, Feind CR, Herter FP, Slanetz CA, Weinberg JA, eds. The Lymphatics in Cancer. Philadelphia, PA: W.B. Saunders; 1972:399-436.

28. Statius Muller MG, van Leeuwen PAM, van Diest PJ, et al. Pattern and incidence of first site recurrences following sentinel node procedure in melanoma patients. World J Surg. 2002;26:1405-1411.

29. Haagensen CD. Lymphatics of the breast. In: Haagensen CD, Feind CR, Herter FP, Slanetz CA, Weinberg JA, eds. The Lymphatics in Cancer. Philadelphia, PA: W.B. Saunders; 1972:300-398.

30. Matter M, Besseghir N, Antonescu C, Genton C-Y, Delaloye J-F. Internal mammary (IM) sentinel node $(\mathrm{SN})$ detection and excision in breast cancer [abstract]. Eur J Cancer. 2001;37(suppl):185-186.

31. Hidden G. Physiology of the lymphatic circulation. Anat Clin. 1979;1:331-345.

32. Menes TS, Schachter J, Steinmetz AP, Hardoff R, Gutman H. Lymphatic drainage to the popliteal basin in distal lower extremity malignant melanoma. Arch Surg. 2004;139:1002-1006.

33. Hatta N, Morita R, Yamada M, Takehara K, Ichiyanagi K, Yokoyama K. Implications of popliteal lymph node detected by sentinel lymph node biopsy. Dermatol Surg. 2005;31:327-330.

34. Sholar A, Martin RCG II, McMasters KM. Popliteal lymph node dissection. Ann Surg Oncol. 2005;12:189-193.

35. Cochran AJ, Wen DR, Huang RR, Wang HJ, Elashoff R, Morton DL. Prediction of metastatic melanoma in nonsentinel nodes and clinical outcome based on the primary melanoma and the sentinel node. Mod Pathol. 2004; 17:747-755. 